\title{
Mapping the Causes of Time, Cost Overruns and Quality Shortfall in Egyptian Public Highway Projects
}

\author{
Ahmed Yousry Akal ${ }^{1}$, Ahmed Ebrahim Abu El-Maaty ${ }^{2}$, Saad El-Hamrawy ${ }^{2}$ \\ ${ }^{1}$ Department of Civil Engineering, Higher Institute for Engineering and Technology, Kafr El-Sheikh, Egypt \\ ${ }^{2}$ Department of Civil Engineering, Menoufia University, Shibeen El-kom, Egypt
}

Email address:

a_yousry85@yahoo.com (A. Y.Akal)

To cite this article:

Ahmed Yousry Akal, Ahmed Ebrahim Abu El-Maaty, Saad El-Hamrawy. Mapping the Causes of Time, Cost Overruns and Quality Shortfall in Egyptian Public Highway Projects. European Business \& Management. Vol. 3, No. 6, 2017, pp. 120-126. doi: 10.11648/j.ebm.20170306.14

Received: October 5, 2017; Accepted: October 28, 2017; Published: November 25, 2017

\begin{abstract}
Transportation infrastructure development specifically public highway projects remains a major tool for achieving the aspirations of the newly introduced economic principles of the Government of Egypt. However, the importance of this industry and its impact on the national economy, concerns are raised frequently on the poor performances of these projects in terms of time, cost, and quality which directly subjected the construction of these projects to schedule delay, cost overrun, and quality shortfall problems. The main objective of the current study is to identify the causal causes of theses overruns in the public highway projects in Egypt. Using a detailed literature review and questionnaire surveys, the results of the study confirmed the prevalence of schedule delay, cost escalation, and quality shortfall in public highway projects in Egypt. Furthermore, the study establishes that contractor's technical staff is insufficient and ineligible to accomplish the project, lack of communication between the construction parties, and unavailability of experienced staff in the owner's and contractor's teams during the project execution are the major factors responsible for causing schedule delay, cost overrun, and quality shortfall respectively. In addition, recommendations for avoiding and overcoming the negative implications of these factors on the performance of the public highway projects in Egypt have been emphasized.
\end{abstract}

Keywords: Time Overrun, Delay, Cost Overrun, Cost Escalation, Quality Shortfall, Highway Projects

\section{Introduction}

It is a well-known fact that investments in economic infrastructure such as bridges and roads are critically important for the long term growth of a country [1]. However, public works sector programs such as highway construction are increasingly being criticized for delivering projects that fail to meet the following: 1) perceived/expected project objectives, 2) delivery within a reasonable amount of time, and 3) costs within their budgeted amounts [2]. In highway projects delay, budget overrun, and the lower level of quality are very scary problems because of their implications are not limited to cause time overrun, cost escalation, additional maintenance and repair works or lawsuits between owners and contractors, but their effects have an immeasurable cost implication to the society; which in turn limits the growth potential of the economy at large and, consequently, frustrates the country development [3-7].
The problems of delay, budget overrun, and quality shortfall in the construction of highway projects become frequent phenomena. For instance, Al-Battaienh [8] in his study reported that the road projects in Jordan are subjected to extensive delay and cost overrun with average time and cost growth $=60.45 \%$ and $12.45 \%$ respectively. In Cameroon, Akoa [9] found that the mean of time and cost overruns rates in road construction projects which had been constructed between 1994 and 2009 are $10.43 \%$ and 5.5\% respectively. Further, Bubshait [10] in Saudi Arabia, Kaliba et al. [11] in Zambia, and Otim and Alinaitwe [12] in Uganda stated that quality performance of many road projects in their countries are below the desired and the standard levels.

Most recently, Akal and Abu El-Maaty [13] in Egypt highlighted that quality shortfall and short-term pavement performance problems have been noted on several highways 
in Egypt during the past ten years. Moreover, Abu El-Maaty et al. [14] conducted a study on a sample of 56 road projects in Egypt in order to judge these projects' performance and determine whether these projects suffer from the issues related to time and cost or not. The results of the field survey showed that all the surveyed projects suffering from time and cost overruns with average percentage $=73.80 \%$ and $46.30 \%$ respectively. According to Akal et al. [15] project completed in time, project completed within budget, and construction in quality are the prime measures for highway projects success. Furthermore, in order to increase the national's economy benefits of the road construction projects in Egypt these projects have to be delivered without quality shortfall, time overrun, and cost escalation [14]. For that, it is of key importance to accomplish this study, in order to identify the casual causes of the previously mentioned issues (poor quality level, delay, and cost overrun), and set recommendations to avoid and overcome the negative implications of these overruns on the performance of the public highway projects in Egypt.

\section{Literature Review}

In this paper, the literature review is undertaken in two fields. While the first field includes the factors influencing delay and cost overrun of highway projects, the second field comprises the major factors influencing the quality performance. In the first field, Mansfield et al. [16] investigated the delay and cost overrun in Nigerian highway projects. Sixteen factors were identified. A field survey was conducted through a questionnaire including contractors, consultants, and client organizations. According to the contractors surveyed the most important delay and cost overrun factor was financing and payment of completed works. While, poor contract management was ranked by the consultants and clients owners as the most significant factor causing delay and cost overrun.

In Thailand, Meeampol et al. [17] investigated the cost and time performance of highway projects from the viewpoint of the public owner. The results of the study revealed quality management, budget management, human resource management, owner involvement, and team relationships impede time performance. While, schedule management and human resource management inhibit cost performance. Vidalis and Najafi [18] undertook a study to determine the causes of cost and time overruns in highway projects of the Florida Department of Transportation (FDOT). From the analysis of over 700 FDOT projects, it was found that the majority of cost and time overruns were due to design factors, changed conditions, designer errors, and omissions by the consultants. Kaliba et al. [11] highlighted that delay of road construction projects in Zambia are caused by factors such as delayed payments, financial processes and difficulties on the part of contractors and clients, contract modification, economic problems, and materials procurement. While, bad or inclement weather due to heavy rains and floods, scope changes, environmental protection and mitigation costs, schedule delay, strikes, and technical challenges are the major causes of cost escalation in Zambia's road construction projects.

Another study has been conducted by Nasir et al. [19] in Pakistan in order to investigate key factors causing cost and time overruns in highway projects through literature review and questionnaire survey. The results of the study showed that factors like delay in progress payments to contractors, land acquisition process, price escalation of major construction materials, improper planning, contractor's incapability to do the job, delay in handing over the site to the contractor, additional work / scope changes, and inappropriate government policies and priorities were identified to had a severe effect on the duration and cost of a highway project in Pakistan.

In the second field which comprises the major factors influencing the quality performance of highway projects, Bubshait [10] concluded that various parameters directly and indirectly contribute to the highway quality performance. The contributing factors are design, specifications, environment, and construction-related factors, while the indirect factors are managerial-related factors. Further, Otim and Alinaitwe [12] stated that the quality performance of road construction projects is highly affected by scarcity of road construction materials. Al-Hassan [20] conducted a study to determine the factors that contribute to the quality of pavement performance in Saudi Arabia. The study had been achieved via both comprehensive literature review and highway contractor's survey. Fifty-nine factors were explained and ranked according to their effectiveness index. Analysis of this study showed that the top five factors affecting the pavement quality and their effectiveness index were greater than $90 \%$ are pavement not designed to the regional conditions, consistency of specification interpretation of aggregate quality, aggregate quality, amount of filler materials in the mixture, and availability of the specified material quality.

This brief review of the literature reveals the following points:

a. Factors causing delay, cost overrun, and quality shortfall in highway projects vary from one country to another.

b. Few studies have been conduced to identify the causes of quality shortfall in highway projects.

c. All the researchers preferred to identify the causes of delay, cost overrun, and quality shortfall through the application of questionnaire survey. Therefore, the authors suggest to use the same methodology in the current study.

\section{Research Methodology}

This research is on the basis of a survey designed to gather all necessary information in an effective way. A questionnaire has been developed in order to investigate the prevalence and occurrence of schedule delay, cost escalation, and quality shortfall issues in public highway projects in Egypt. Furthermore, identifying the casual causes of the previously 
mentioned overruns. The studied target population includes owners, consultants, and contractors who have experience not less than ten years in the construction of public highway projects in Egypt. Furthermore, the collected data from the respondents to the questionnaire have been analyzed using the average weighted percentage method. In addition, recommendations for minimizing delay, cost overrun, and quality shortfall in construction projects will be suggested in view of the results of the study.

\subsection{Questionnaire Design}

The designed questionnaire is divided into three main parts. The first part includes general information questions about the respondents such as his/her name (optional) and relevant working experience. While, the second part is designed to ask the respondents about the prevalence and occurrence of schedule delay, cost escalation, and quality shortfall issues for the public highway projects in Egypt they have experienced. Finally, the third part has been developed in order to ask the participants in the questionnaire to identify and rate the casual causes of delay, cost overrun, and quality shortfall with respect to their significance on a Likert scale ranging from 1 to 4 , where $1=$ not significant, $2=$ slightly significant, $3=$ significant, and $4=$ very significant.

\subsection{Data Collection}

A very important step in the data collection process is to select the sample size. From many experienced practitioners contacted, 59 were willing to participate in the study. All the respondents were involved in the construction of public highway projects in Egypt with experience not less than ten years in this industry. The appropriateness of a small-sample size is not uncommon issue in the construction management studies. For instance, the sample size of the studies of Tah et al. [21], Chua et al. [22], Fallahnejad [23], Gudiene et al. [24], and Abu El-Maaty et al. [25] were 7, 20, 23, 5, and 5, respectively. Thus, the sample size of the present study compares favorably with those reported in earlier relevant studies.

\subsection{Data Analysis}

The suggested delay, cost overrun, and quality shortfall causes in public highway construction projects are ranked by the measurement of the average weighted percentage. The following formula is used to rank them on the basis of significance level as identified by the participants:

$$
\mathrm{WA}=\frac{1}{4} \times \frac{\sum \mathrm{Fi} \mathrm{Ri}}{\sum \mathrm{Fi}} \times 100
$$

Where:

WA: is the average weighted percentage;

$\mathrm{Fi}$ : is the frequency or total number of respondents choosing response type $\mathrm{i}$ on the Likert scale, with $\mathrm{i}$ ranging from 1 to 4 as earlier described.

$\mathrm{Ri}$ : is the response type on the Likert scale, i ranging from 1 to 4 on the Likert scale;

Accordingly, if all participants answer one cause to be no not significant, then WA is $25 \%$, meaning that this cause is not relevant and the last in rank. Conversely, if all answer very significant, then WA is 100 , meaning that this cause is very relevant and is the first in rank. In the current study the causes whose WA score is $90 \%$ and above will be categorized as the major factors that cause schedule delay, cost escalation, and quality shortfall in public highway construction projects in Egypt.

\section{Research Findings and Discussions}

This section presents the findings and discusses the results from the respondents to the questionnaire survey in three areas: a) general characteristics of the respondents to the questionnaire, b) prevalence of time, cost overrun, and quality shortfall issues in public highway projects, and c) major casual causes of delay, cost overrun, and quality shortfall in public highway projects in Egypt.

\subsection{General Characteristics of Respondents}

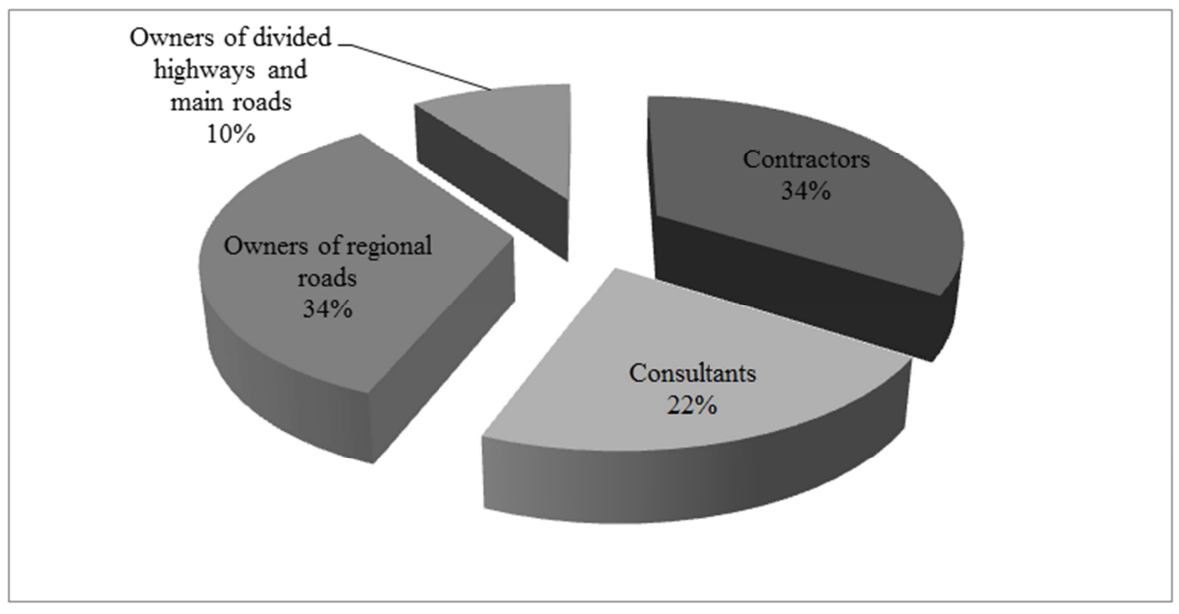

Figure 1. Respondents'organization types. 


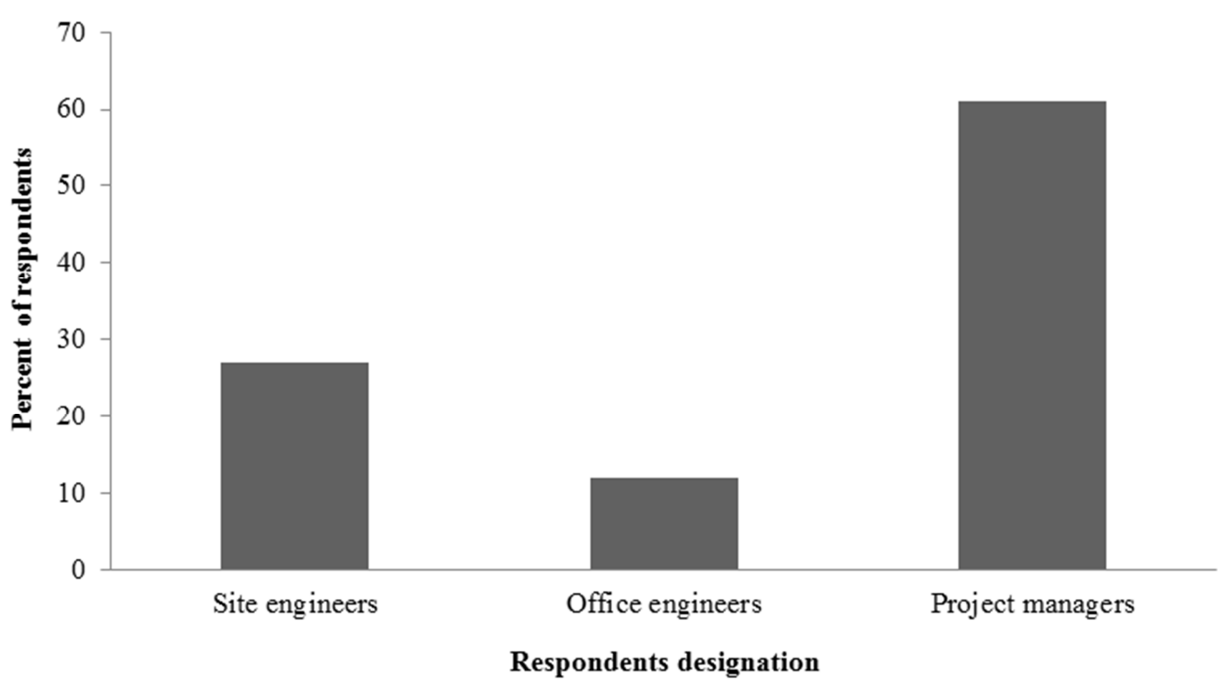

Figure 2. Designation of the respondents.

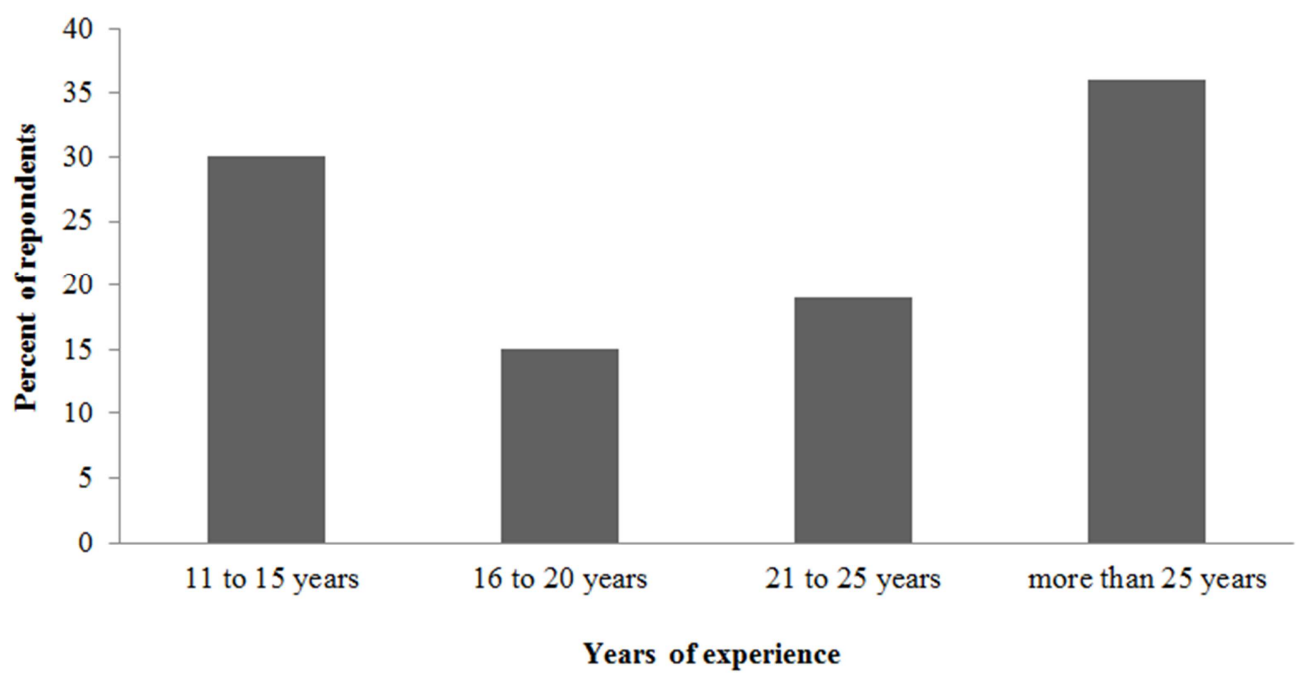

Figure 3. Relevant working experience of the respondents in public highway projects.

The organization type, designation, and relevant experience of the respondents to the questionnaire have been assessed. As shown in Figure 1, out of 59 participants $10 \%$ of the respondents are owners of divided highways and main roads, $34 \%$ are owners of regional roads, $22 \%$ are consultants, and $34 \%$ are contractors. Figure 2 shows the designation of the respondents to the distributed questionnaire. The results of this Figure clarifies that $27 \%$ of the respondents to the questionnaire are site engineers, $12 \%$ are office engineers, and $61 \%$ are project managers. Furthermore, Figure 3 shows the working experience of the respondents in the public highway construction industry, the analysis of this Figure clarifies that $30 \%$ of the respondents have experience in the field of public highway projects between 11 to 15 years, $15 \%$ have experience between 16 to 20 years, $19 \%$ have experience between 21 to 25 years, and $36 \%$ have experience more than 25 years. The results of these Figures shows that the profile and experience of the respondents suggest sufficient exposure to make the information acquired reliable.

\subsection{Prevalence of Time, Cost Overrun, and Quality Shortfall in Public Highway Projects}

There are a general agreement by all the respondents to the questionnaire that delay, cost escalation, and quality shortfalls are frequent and prevalent phenomena in the majority of the public highway construction projects in Egypt.

\subsection{Major Causes of Time Overrun}

Table 1 shows the major causes of time overrun according to the perspectives of the respondents to the questionnaire. The analysis of this Table shows that there are five major causes of time overrun that predominantly affect public highway construction projects in Egypt. The contractor's technical staff is insufficient and ineligible to accomplish the project is classified as the first factor causing schedule delay. While, owner delay in freeing the main contractor financial payments and lack of the equipment efficiency have been ranked as the second factor contributing to delay of public 
highway projects. Difficulties in financing the project by the contractor and shortage of equipment and construction materials which all scored $90 \%$ have been identified as the third factor responsible for causing time overrun.

Table 1. Average weighted percentage of time overrun causes.

\begin{tabular}{lll}
\hline Sr. & Cause & Average weighted percentage (\%) \\
\hline 1 & Contractor's technical staff is insufficient and ineligible to accomplish the project & 95 \\
2 & Owner delay in freeing the main contractor financial payments & 91 \\
3 & Lack of the equipment efficiency & 91 \\
4 & Difficulties in financing the project by the contractor & 90 \\
5 & Shortage of equipment and construction materials & 90 \\
\hline
\end{tabular}

\subsection{Major Causes of Cost Overrun}

Table 2 presents the major causes of cost overrun with respect to the viewpoints of the respondents to the questionnaire. The analysis of this Table shows that there are seven major causes influencing the budget performance and leading to project cost overrun. Lack of communication between the construction parties is classified as the first factor causing project cost overrun. While, inadequate preparation of the project concerning planning and execution and lack of costs following-up during the project execution by the construction parties have been ranked as the second and the third factors contributing to cost escalation of public highway projects. The increase in the price of the project construction materials, low speed of decision making by each team involved in the project, equipment failure for work at the site, and inaccurate review for drawings and contract document which all scored $93 \%$ have been identified as the fourth factor responsible for causing project cost overrun.

Table 2. Average weighted percentage of cost overrun causes.

\begin{tabular}{lll}
\hline Sr. & Cause & Average weighted percentage (\%) \\
\hline 1 & Lack of communication between the construction parties & 97 \\
2 & Inadequate preparation of the project concerning planning and execution & 96 \\
3 & Lack of costs following-up during the project execution by the construction parties & 95 \\
4 & The increase in the price of the project construction materials & 93 \\
5 & Low speed of decision making by each team involved in the project & 93 \\
6 & Equipment failure for work at the site & 93 \\
7 & Inaccurate review for drawings and contract documents & 93 \\
\hline
\end{tabular}

\subsection{Major Causes of Quality Shortfall}

The perspectives of the respondents to the questionnaire survey regarding the main causes of quality shortfall in public highway projects in Egypt have been presented in Table 3. The analysis of this Table shows that seven factors have been identified to have a major effect on the quality level. Unavailability of experienced staff in the owner's and contractor's teams during the project execution has been ranked as the most important factor that cause quality shortfall with average weighted percentage $=97 \%$. The second important factor responsible for causing quality shortfall as perceived by the respondents is asphalt quality and type used in the construction process is imperfect with average weighted percentage $=93 \%$. While, absence of clear and detailed program for quality management to be adhered by the owner, consultant and contractor, pavement is not designed according to the regional conditions, and unavailability of the specified materials quality have been ranked as the third most important causes of quality shortfall with average weighted percentage $=92 \%$. Finally, lake of clarity of responsibilities and roles for each one of the owner, consultant and contractor and inefficiency of the owner's inspection team have been ranked as the least factors that cause quality shortfall with average weighted percentage $=$ $91 \%$.

Table 3. Average weighted percentage of quality shortfall causes.

\begin{tabular}{lll}
\hline Sr. & Cause & Average weighted percentage (\%) \\
\hline 1 & Unavailability of experienced staff in the owner's and contractor's teams during the project execution & 97 \\
2 & Asphalt quality and type used in the construction process is imperfect & 93 \\
3 & Absence of clear and detailed program for quality management to be adhered by the owner, consultant and & 92 \\
4 & contractor & \\
5 & Pavement is not designed according to the regional conditions & 92 \\
6 & Lnavailability of the specified materials quality & 92 \\
7 & Inefficiency of the owner's inspection team & 91 \\
\hline
\end{tabular}

\section{Conclusions}

The construction of an integrated highway network promotes sustainable development of the national economy of any country whether developing or developed. Furthermore, improving highways construction efficiency by means of quality effect, cost-effectiveness, and timeliness would certainly contribute to cost savings for the country as a 
whole. In an effort to improve the national economy of Egypt by improving its transportation system, this study has been conducted to identify the major factors responsible for causing delay, cost overrun, and quality shortfall in public highway projects in Egypt.

According to the results presented in this study, the following conclusions can be drawn:

a). The major factors responsible for causing delay in public highway projects in Egypt are:

1. Contractor's technical staff is insufficient and ineligible to accomplish the project.

2. Owner delay in freeing the main contractor financial payments.

3. Lack of the equipment efficiency.

4. Difficulties in financing the project by the contractor.

5. Shortage of equipment and construction materials.

b). The casual causes of project cost overrun in public highway projects in Egypt are:

1. Lack of communication between the construction parties.

2. Inadequate preparation of the project concerning planning and execution.

3. Lack of costs following-up during the project execution by the construction parties.

4. The increase in the price of the project construction materials.

5. Low speed of decision making by each team involved in the project.

6. Equipment failure for work at the site.

7. Inaccurate review for drawings and contract documents.

c). Quality shortfall in public highway projects in Egypt arise from the following factors:

1. Unavailability of experienced staff in the owner's and contractor's teams during the project execution.

2. Asphalt quality and type used in the construction process is imperfect.

3. Absence of clear and detailed program for quality management to be adhered by the owner, consultant and contractor.

4. Pavement is not designed according to the regional conditions.

5. Unavailability of the specified materials quality.

6. Lack of clarity of responsibilities and roles for each one of the owner, consultant and contractor.

7. Inefficiency of the owner's inspection team.

\section{Recommendations}

In view of the previous analysis and conclusion, the following points can be recommended in order to improve the public highway projects performance in Egypt in terms of quality, time, and cost:

1. It is recommended to the construction parties to develop plans and programs for training their staff in order to improve their skills and qualifications through the presence of human resources department responsible for handling professionals and staff training.

2. Effective highway design is one of the more important aspects that influencing the project life time. Design errors made by designers due to inadequate level of experience, inadequate engineer assumptions and inaccurate data make it important for owner to employ experienced designers capable of adjusting all conditions with their design in order to overcome the negative sequences of such problems on the project objectives.

3. The construction of highway projects consists of numerous parties: owner, contractor, and consultant each of which has a role to play in delivering the project in accordance with its objectives. Therefore, the contract document should shape in a clear manner the contractual relationship between the project's parties in order to avoid any conflict/ discrepancy.

4. Delayed payments due to complex financial processes in owner or contractor organizations directly lead to late completion of projects. Therefore, it is recommended for the owners to ensure that they have funds available for projects before they are commissioned. Furthermore, during the bidding process it is too important to check the financial capabilities of all competitors in order to reduce the risk of awarding the contract to un financially sound contractor.

5. Shortage of construction materials and equipment are major problems affecting the project time schedule. Therefore, it is recommended to the contractors to maintain buffer stocks of material in keeping with the scheduling of project procurement plan. Furthermore, the technical evaluation of the competitors must investigate the capabilities of the contractor to provide the project with the required equipment.

6. It is recommended to the contracting companies to prepare a brief technical study about the project characteristics before introducing the tender. This will help in identifying all the factors, risks, and uncertainties that may affect directly or indirectly on estimating the project cost and, consequently, limiting the exposure of the project to be delivered overrunning the estimated budget.

7. The contractors should develop plans and scheduling for their projects. This action will help in following-up the project activities in terms of time and cost and determine whether the project is over or under the estimated time and cost and, consequently, take the necessary action in the suitable time toward any overrun in the project duration or budget.

8. It is imperative to establish appropriate formal communication channels among the construction parties during the conceptual phase in order to provide faster data sharing, increasing the efficiency of site operations, and making practitioners to take decision at earliest in solving any problem occurring during the project execution. 


\section{References}

[1] Kokkaew, N. and Rudjanakanoknad, J. (2017). Green assessment of Thailand's highway infrastructure: a green growth index approach. KSCE Journal of Civil Engineering, 1-12. doi: 10.1007/s12205-017-0923-0.

[2] Lee, M., Lim, J., and Hunter, J. (2010). Performance-based value engineering application to public highway construction. KSCE Journal of Civil Engineering, 14(3), 261-271.

[3] Thurner, H. (2001). Quality assurance and self-control in road construction, advanced measurement technology. Technical Paper, Geodynamic AB, Stockholm, Sweden 11, 1-10.

[4] Rwakarehe, E. and Mfinanga, D. (2014). Effect of inadequate design on cost and time overrun of road construction projects in Tanzania. KICEM Journal of Construction Engineering and Project Management, 4(1), 15-28.

[5] Hasan, R., Suliman, S., and Al Malki, I. (2014). An investigation into the delays in road projects in Bahrain. International Journal of Research in Engineering and Science, $2(2), 38-47$

[6] Seboru, M. (2015). An Investigation into factors causing delays in road construction projects in Kenya. American Journal of Civil Engineering, 3(3), 51-63.

[7] Ram, A. and Paul, P. (2015). Study on construction sequence delay for road infrastructure projects. IOSR Journal of Mechanical and Civil Engineering, 12(2), 15-21.

[8] Al-Battaienh, H. (1999). Information system of progress evaluation of public projects in Jordan. M. S. Thesis, Jordan University of Sciences and Technology.

[9] Akoa, B. (2011). Cost overruns and time delays in highway and bridge projects in developing countries experience from Cameroon. M. S. Thesis, Michigan State University.

[10] Bubshait, A. (2001). Quality of pavement construction in Saudi Arabia. Practice Periodical on Structural Design and Construction, 6(3), 129-136.

[11] Kaliba, C., Muya, M., and Mumba, M. (2009). Cost escalation and schedule delays in road construction projects in Zambia. International Journal of Project Management, 27(5), 522-531.

[12] Otim, G. and Alinaitwe, H. (2013). Factors affecting the performance of pavement road construction projects in Uganda. In: Proceedings, SB13 Southern Africa: creating a resilient and regenerative built environment, Cape Town, Southern Africa.

[13] Akal, A. and Abu El-Maaty, A. (2016). Fuzzy assessment of factors influencing quality level of highway projects. International Journal of Management and Fuzzy Systems, 2(2), 6-14.
[14] Abu El-Maaty, A., Akal, A., and El-Hamrawy, S. (2018). The iron triangle of projects management: quality, schedule and cost of road infrastructure projects in Egypt. In: Proceedings, Calautit J, Rodrigues F, Chaudhry H, Altan H (eds) towards sustainable cities in Asia and the Middle East. GeoMEast 2017. Sustainable Civil Infrastructures. Springer, Cham.

[15] Akal, A., Abu El-Maaty, A., and El-Hamrawy, S. (2016). A circular framework for evaluating highway construction projects success: AHP approach. Civil Engineering Journal, 2(7), 324-333.

[16] Mansfield, N., Ugwu, O., and Doran, T. (1994). Causes of delay and cost overruns in Nigerian construction projects. International Journal of Project Management, 12(4), 254-260.

[17] Meeampol, S. and Ogunlana, S. (2006). Factors affecting cost and time performance on highway construction projects: evidence from Thailand. Journal of Financial Management of Property and Construction, 11(1), 3-20.

[18] Vidalis, S. and Najafi, F. (2002). Cost and time overruns in highway construction. In: Proceedings, $4^{\text {th }}$ transportation specialty conference of the Canadian society for civil engineering, Montreal, Quebec, Canada.

[19] Nasir, A., Gabriel, H., and Choudhry, R. (2011). Cost and time overruns in highway projects of Pakistan. In: Proceedings, $6^{\text {th }}$ international conference on construction in the $21^{\text {st }}$ century, Kuala Lumpur, Malaysia.

[20] Abdul-Hamid, A. (1993). Factors affecting quality of pavement construction in Saudi Arabia. M. S. Thesis, King Fahd University of Petroleum and Minerals.

[21] Tah, J., Thorpe, E., and McCaffer, R. (1994). A survey of indirect cost estimating in practice. Construction Management and Economic, 12(1), 12-36.

[22] Chua, D., Kog, C., and Loh, P. (1999). Critical success factors for different project objectives. Journal of Construction Engineering and Management, 125(3), 142-150.

[23] Fallahnejad, M. (2013). Delay causes in Iran gas pipeline projects. International Journal of Project Management, 31(1), 136-146.

[24] Gudiene, N., Banaitis, A., Podvezko, V., and Banaitiene, N. (2014). Identification and evaluation of the critical success factors for construction projects in Lithuania: AHP approach. Journal of Civil Engineering and Management, 20(3), 350359 .

[25] Abu El-Maaty, A., El-Hamrawy, S., and Akal, A. (2016). Success factors of highway construction projects in Egypt: AHP approach. KICEM Journal of Construction Engineering and Project Management, 6(4), 7-14. 